\title{
Analysis of Smart Home use based on the Degree of Health-related Risk Variation: A Cross - Sectional National Survey in China
}

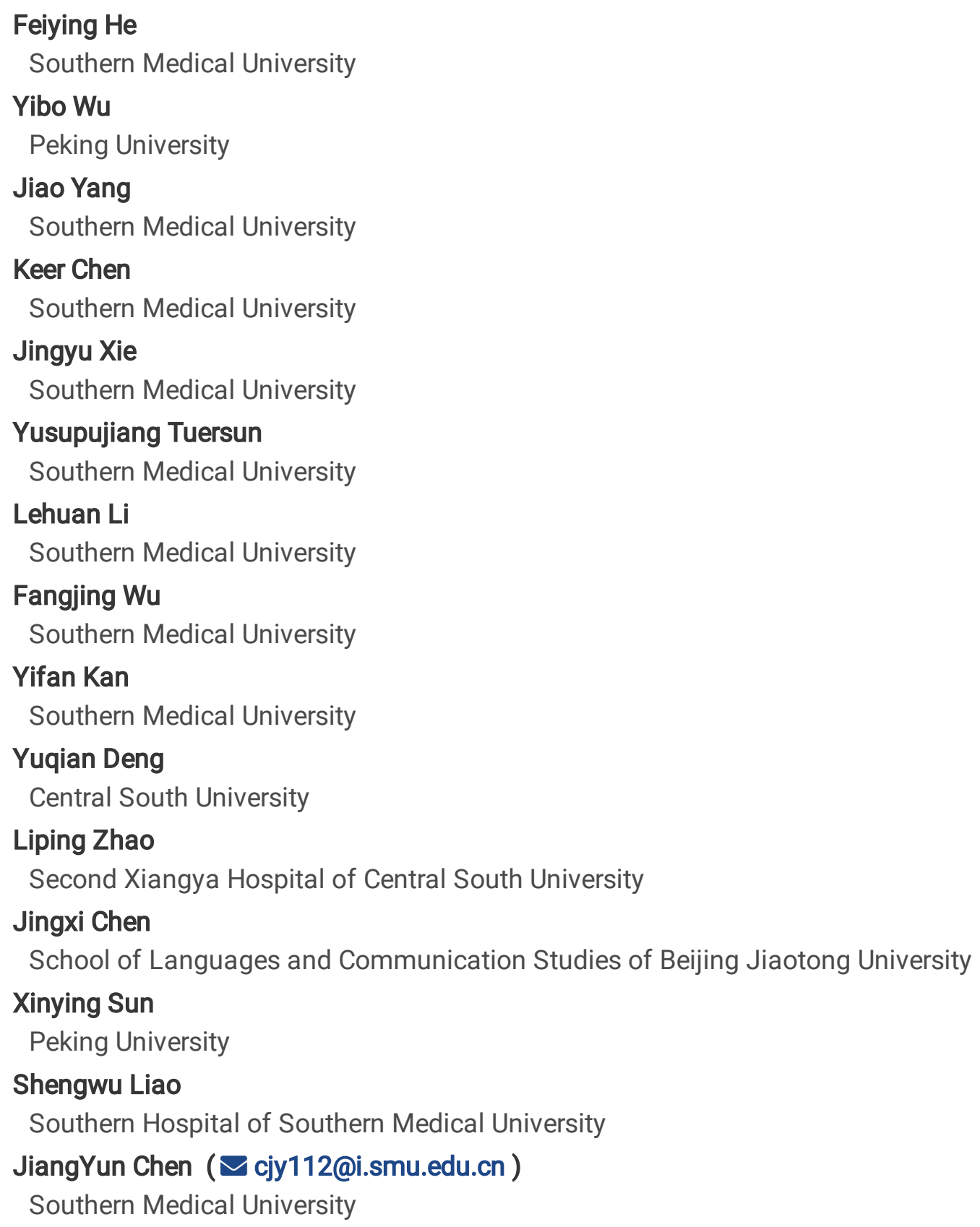

\section{Research Article}

Keywords: Smart Home, Digital Health, Health-related Risk, Clustering, China Family Health Index Survey

Posted Date: December 20th, 2021 
DOI: https://doi.org/10.21203/rs.3.rs-1151869/v1

License: (c) (i) This work is licensed under a Creative Commons Attribution 4.0 International License. Read Full License 


\section{Abstract}

\section{Background}

Digital health has become a heated topic today and smart homes have received much attention as an important area of digital health. However, most of the existing studies have focused on discussing the impact of smart homes on people or the attitudes of older people towards smart homes. Only few studies have focused on relationship between health-related risks and use of smart homes.

\section{Aims}

To investigate the association between health-related risks and the use of smart homes, provide new recommendations to promote the implementation of digital health strategies and achieve health for all.

\section{Methods}

We used data from 11,031 participants aged 18 and above. The population was clustered based on five health-related risk factors: perceived social support, family health, health literacy, media use, and chronic diseases self-behavioral management. A total of 23 smart homes were categorized into three sub-categories: entertainment smart home, functional smart home, and health smart home. We analyzed demographic characteristics and utilization rate of smart home across different cluster.

\section{Results}

The participants were clustered into three groups: low risk, meddle risk, and high risk. The utilization rate of smart home was the most popular in the low risk group (total smart home: $86.97 \%$; entertainment smart home: $61.07 \%$, functional smart home: $77.42 \%$, and health smart home: 75.33\%; $p$ 0.001). For entertainment smart home, smart TV had the highest utilization rate (low risk: $45.73 \%$; middle risk: $43.52 \%$, high risk: $33.38 \%, p<0.001$ ). For functional smart home, smart washing machine (low risk: $37.66 \%$, middle risk: $35.11 \%$, high risk: $26.49 \% ; p<0.001$ ) and smart air conditioner (low risk: 35.95\%, middle risk: $29.13 \%$, high risk: $24.61 \%$ ) were higher than other of this category. For health smart home, sports bracelet has the highest utilization rate (low risk: $37.29 \%$, middle risk: $24.49 \%$, high risk: $22.83 \%$ ).

\section{Conclusion}

Health-related risks are an important factor affecting the use of smart homes. Joint efforts of government and product manufacturers are needed to broaden the smart home market and promote the implementation of digital health strategies.

\section{Introduction}

Along with accelerated industrialization, urbanization, and population aging, China's disease spectrum continues to change. The death rate from chronic non-communicable diseases is in the proportion to $88 \%$ of all deaths. The resulting disease burden accounts for over $70 \%$ of the total disease burden. China government developed a "Healthy China" strategy in $\mathbf{2 0 1 7}$ to improve the health literacy of residents, prevent diseases, and improve the quality of life of residents [1]. The Internet of Things has experienced rapid growth in the past decade, covering many fields, critical digital health. Following the development trend of technology, the World Health Organization has proposed a global digital health strategy for 2020-2025, advocating the promotion of digital health and the application of digital health to achieve the goal of universal health[2]. To help drive the development of health in China, the government is also using 
Internet technology. It has been continuously focusing on the innovative home sector since 2008, promulgating policy documents to support the development of smart homes[3].

Constantly developing smart homes are an important role in digital health and can effectively alleviate many health problems. From an age perspective, stress and fatigue from school or work endanger young people's physical and mental health. Studies have shown that work stress is a significant risk factor for colorectal, lung, and oesophageal cancers[4]. Treatments to reduce stress and exhaustion in concert with other therapies can make adolescent depression treatment more effective[5]. Service robotic massage systems with human behavioral sensing can effectively relieve users of physical fatigue, leading to physical and mental relaxation and a higher quality of life [6]. Smart homes can also effectively mitigate the impact of aging. For older adults with deteriorating physical functions, reduced mobility become a significant problem in their lives. Homes intelligently set up can automatically adapt to their behavior and reduce inconvenience, such as intelligent adaptive toilets [7]. In addition, visual impairment also seriously affects the health of the elderly, such as falls, loneliness, and depression, and intelligent lighting devices can dynamically adjust the light to alleviate this problem effectively [8]. Empty nesters live alone all year round and suffer from social isolation and loneliness, seriously affecting their health and quality of life [9]. Smart homes connected to the Internet can establish a connection between the elderly and the outside community, and smart homes with entertainment properties can also alleviate the loneliness of the elderly living alone [10]. From the perspective of special populations, smart speakers can help people with disabilities who have communication difficulties enhance their understanding of speech and improve their communication [11]. Remote support services can help enhance the sense of security provided by people with intellectual and related developmental disabilities [12]. From a more macro perspective, smart homes can effectively relieve pressure on the healthcare system. By connecting to the Internet, smart homes can monitor and deliver disease and health information to healthcare institutions in real time, benefiting both users and healthcare institutions [13].

The report "China Internet Development 2021" released by the Internet Society of China shows that China's Internet penetration rate has reached $70.4 \%$, the internet of things market size reached 1.7 trillion yuan, the artificial intelligence market size rose to 303.1 billion yuan, and the market size of online medical and health services climbed to 196.1 billion yuan [14], which in general means that China has a good Internet foundation to carry out digital health. However, research shows that the development and popularity of smart homes in China are policy-driven rather than demanddriven [3]. There is still space to improve the market scale. To expand the smart home market, improve people's quality of life and promote the implementation of the health China strategy, it is necessary to deeply study the real needs of consumers and promote the structural reform from the supply side from the demand side.

Much attention has been paid to research on smart homes in recent years. However, most of them have been considered from the perspectives of their effects and impacts on people $[15,16]$ and people's attitudes towards smart homes $[17,18]$. In contrast to previous studies, our study clustered populations according to health-related risk factors and analyzed the characteristics of different groups and their use of smart homes. Frija-Masson J[15] investigated whether smart scales are more accurate in weight and body composition than dual X-ray absorptiometry (DEXA) that is the gold standard, and showed that smart scales are not a substitute for DEXA. New smart robots, walkers, can proactively approach users in complex indoor environments and avoid obstacles to improve mobility safety[16]. Sajay Arthanat reveals the extent of smart home technology adoption among seniors, finding varying rates of adoption of specific types of devices with carbon monoxide alarms reaching $81.5 \%$ of respondents and water leak detectors and automatic oven shut-offs ranking in the top two categories of potential usage among the 13 products surveyed at $41.8 \%$ and $38 \%$ respectively, with these types of safety products. These safety products are more popular with the older age group. At the same time, voice-activated assistants and motion-activated cameras were not used by $63.5 \%$ and $67 \%$ of respondents, respectively, with lower usage and potential usage of these innovative and trendy products[17].

Page $4 / 29$ 
Jachan DE compared older people's satisfaction with smart homes with traditional mobility support tools and value for money. Overall, users rated all installed smart homes higher in terms of satisfaction. In terms of value for money, smart homes are of higher quality but also more expensive. The authors suggest that products can be modularized, thus reducing smart home product prices[18].

Different groups of people have various needs for smart homes, and expanding the smart home market requires understanding the needs of the audience on different sides of the product. The development of products cannot be separated from the support of technology and policies. In the context of the continuous development of the Internet and the much attention paid to the digital health strategy, understanding the differences in smart home needs of people with different health-related risks is conducive to smart homes producing products that meet consumer needs and promoting the development of this market, which can also, in turn, promote the effective implementation of the digital health strategy.

\section{The present study}

The role of health-related risks in the link between smart home use has not been explored in previous studies, despite the profound impact of health-related risks on the smart home use. The aim of this study is to examine the role of health-related risk in linking smart home use in China. Based on the above literature review, the following hypotheses are proposed.

\section{Hypothesis 1}

The health-related risk is negatively associated with smart home use. The lower the health-related risk is, the better the smart homes are used.

\section{Hypothesis 2}

Different health-related risk groups will prioritize different types of smart homes.

\section{Method}

\section{Data and Procedure}

The data used in this study is conducted in 23 provinces, 5 autonomous regions, and 4 municipalities directly under the central government from July to September 2021. The survey is a multi-stage sampling, using the random number table method to select 2-6 cities from each noncapital prefecture-level administrative region of each province and an autonomous region, a total of 120 cities; based on the data results of "the seventh national census in 2021", quota sampling (quota attributes are gender, age, and urban-rural distribution) was conducted for 120 urban residents, so that the gender, age and urban-rural distribution of the samples basically conform to the demographic characteristics. Finally, 11031 valid questionnaires were obtained that have high quality and accurate national representation and comply with the ethical review rules (JNUKY-2021-018).

\section{Variables}

\section{Characteristic Variable}


The characteristic variable in this study included respondents' socio-economic background (age, gender, income, Hukou, residence, education, public insurance, location recently, chronic disease, Disability, work status and Politics), family characteristics (Marriage, family type, number of children, household) and lifestyle (drinking status). See Supplementary Table S1 for details of definitions and classifications.

\section{Smart Home Use}

This paper investigates the Smart Home Use (SHU) of people for 23 kinds of smart homes, and divides them into three categories according to the functions of smart homes: entertainment SHU (consists of Smart TV, VR glasses, body sensing car, smart speaker), function assistance SHU (consists of a smart robot, smart lighting, smart washing machine, smart switch, smart door lock, smart toilet, smart mosquito repellent, electric curtain, smart air conditioner, smart clothes hanger, smart monitoring) and health SHU (consists of sports bracelet, temperature and humidity sensor, smart socket, danger button, smoke transducer, body fat scale, air purifier, smart medicine cabinet ). At the same time, the utilization rate of smart homes and the composition ratio of people are analyzed.

\section{Health-related Risk}

We identified five factors that influence health-related risk based on previous studies: perceived social support [19], family health [20], health literacy [21], media use [22], and chronic disease self-behavioral management [23]. These five aspects were negatively associated with health-related risk, and we classified health-related risks according to the distribution characteristics of these five aspects.

Perceived social support was measured using The Perceived Social Support Scale (PSSS) based on the Zimet Perceived Social Support Scale. A 12-item scale divided into three dimensions: family support, friend support, and other supports, as shown in Table S2 in the attached table. "strongly disagree", "slightly disagree", "neutral", "slightly agree", "agree", "Strongly agree" seven options, these seven options are assigned a score of 1-7 (Strongly disagree = 1). The higher the score, the higher the perceived social support. The alpha coefficients for family support, friend support, other supports and the full scale were $0.87,0.85,0.91$ and 0.88 for the sample of 275 cases (139 males and 136 females) respectively, with retest reliability of $0.85,0.75,0.72$ and 0.85 [24].

Family health was measured using the Family Health Scale-Short Form (FHS-SF) based on the AliceAnn Crandall [25] (Supplementary Table S3). For each item, subjects rated "strongly disagree", "somewhat disagree", "neither agree nor disagree", "somewhat agree " and "strongly agree", with the three dimensions (7 items) other than "family health resources" being assigned a value of 1-5 in order ("strongly disagree" $=1$ ), while the three items for "family health resources" were assigned the opposite value ("strongly agree"=1). Cronbach's alpha for the 10 -item scale was 0.80 and Cronbach's alpha for the FHS-SF was 0.84 .

Health literacy was measured using the Short-Form Health Literacy Instrument (HLS-SF12) developed by Tuyen V Duong [26]. The scale has 12 items covering the three health domains of health care, disease prevention, and a health promotion, as detailed in Table S6 in the Supplementary Material. "very difficult", "difficult", " easy", and "very easy" for each item, in order of assignment from 1 to 4 ("very difficult" =1). The higher the score is, the higher the health literacy is. This scale has high reliability with a Cronbach's alpha of 0.85 .

In order to find out how the participants use the media, we developed our own media use scale with seven items. The scale has five options: "never use", "occasionally use", "sometimes use", "often use" and "almost every day" that are assigned a value of 0-4 in order (never use $=0$ ), see Table S4 in the Supplementary Material. 
Chronic disease self-behavioral management was measured using the Chronic Disease Self-management Study Measure (CDSMS) developed by Lorig[27, 28]. The scale is divided into two sub scales: self - management behavior and self-management effectiveness. The self-management behavior scale consists of 15 items including exercise, cognitive symptom management practices, and communication with a doctor. The five items were rated on a scale of 0-4 (not done=0), with higher scores resulting in higher status. See Table S5 in the Supplementary Material for details. The Cronbach coefficient for the CDSMS was 0.72-0.75.

\section{Statistical Analysis}

For segmentation, non-hierarchical K-means cluster analysis was conducted based on 5 health-related risk-related factors: family health, health literacy, chronic self-behavior management, perceived social support, and media use. Suppose a factor has a relatively large cluster center value. In that case, it can be characterized as a cluster that is positively affected by the factor. Then we conducted a t-test to explore the differences in the health-related risk-related factors, according to the clustering.

Firstly, we made a descriptive analysis of the demographic characteristics and the characteristics of each Characteristic Variable in the three clusters. The number distribution of each variable in the three clusters, the composition ratio distribution of each variable classification in the same cluster, and the proportional distribution of the same variable classification in the three clusters is counted. Chi-square verification was performed by comparing these data. Thirdly, we also make a descriptive analysis on the overall use of smart homes based on demographic characteristics. The smart home is divided into three categories, plus the overall unused category, and the number of users, the composition ratio, and the utilization rate of the following variables in these four categories are counted. Then, perform chi-square verification. Fourth, we made a descriptive analysis of the needs of the three groups for the specific 23 smart homes under the three categories. We counted the number and the composition ratio of the three groups. Then, perform chisquare verification. Fifthly, according to the above analysis, we mainly focus on the differences in the demand for smart homes among the three variables of residence, gender, and age, and then make a descriptive analysis. The number and the composition ratio of 23 types of smart homes used by people of three age groups with urban and rural residence, male and female gender are counted. Then, perform chi-square verification.

\section{Results}

\section{Segmentation Based on Health-related risk}

As the clustering was more balanced in each group when clustered into three groups and there were significant differences in health-related risk characteristics among the groups, the clustering can be judged that is convincing when clustered into three groups. Table 1 showed the results of the clustering defined into three groups. The analysis shown that there was a significant difference among three clusters in Chronic self-behavior management, Health literacy, Media use, Perceive social support and Family health $(p<0.05)$. 
Table 1

Results of cluster analysis for health-related risk.

\begin{tabular}{|lllll|}
\hline & Cluster 1 & Cluster 2 & Cluster 3 & \multirow{2}{*}{ p-value } \\
\cline { 2 - 4 } & Low Risk & Middle Risk & High Risk & \\
\hline $\mathrm{n}$ & 2679 & 4589 & 3763 & \\
\hline Chronic disease self-behavioral management & $18.82 \pm 5.30$ & $10.45 \pm 2.93$ & $13.18 \pm 5.08$ & $<0.001$ \\
\hline HLS & $40.99 \pm 5.38$ & $36.94 \pm 4.94$ & $33.36 \pm 5.69$ & $<0.001$ \\
\hline Media Use & $17.19 \pm 4.37$ & $10.50 \pm 3.65$ & $11.12 \pm 4.47$ & $<0.001$ \\
\hline PSSS & $68.42 \pm 10.54$ & $65.46 \pm 9.07$ & $47.99 \pm 9.33$ & $<0.001$ \\
\hline FLS & $40.96 \pm 5.94$ & $41.44 \pm 4.71$ & $31.68 \pm 4.06$ & $<0.001$ \\
\hline FLS_ social and emotional health processes & $13.26 \pm 1.82$ & $13.12 \pm 1.65$ & $9.41 \pm 2.04$ & $<0.001$ \\
\hline FLS_ healthy lifestyle & $8.88 \pm 1.25$ & $8.83 \pm 1.13$ & $6.36 \pm 1.43$ & $<0.001$ \\
\hline FLS_ health resources & $10.32 \pm 3.96$ & $11.25 \pm 2.99$ & $9.65 \pm 2.00$ & $<0.001$ \\
\hline FLS_ external social supports & $8.50 \pm 1.37$ & $8.23 \pm 1.30$ & $6.26 \pm 1.35$ & $<0.001$ \\
\hline HLS: Health Literacy Scale; PSSS: Perceived Social Support Scale; FLS: Family Health Score & \\
\hline
\end{tabular}

The clusters were defined and named based on the level of health-related risks and characteristics. cluster 1 'low risk' is a group that the mean values of each variable were each higher than their overall respective mean values. they take the lowest health-related risk. cluster 2 'middle risk' is a group whose mean values are above average except for media use and chronic self-behavior management. their health-related risks are moderate but still require control. cluster'3 'high risk' is the highest health-related risk group that means values lower than average. the difference among the factors for each group can be seen in figure 1.

\section{Descriptive statistics and correlations}

Table 2 shows the demographic and covariant characteristics of each cluster. There was a significant difference in some Characteristic Variables among the three groups. The proportion of females in Cluster1, Cluster2, and Cluster 3 was higher. Among Cluster1, Cluster2, and Cluster 3, the proportion of young and middle-aged people aged $19 \sim 45$ was higher, and the proportion of people aged over 91 was lower. The Middle Income Group of Cluster 1 with income from 3001 to 7500 and the High Income Group of above 7501 were higher than the Middle Income Group of Cluster 2 and Cluster 3 with income from 3001 to 7500. Cluster 1, Cluster 2, and Cluster 3 have a higher proportion of the urban population, and the difference is more obvious in Cluster 1. The other parties in Cluster 1, Cluster 2, and Cluster 3 had higher percentages, and the disparity was even greater in Cluster2. The proportion of postgraduates and doctorates in Cluster1, Cluster2, and Cluster 3 was higher than that in middle school and Lower Education, and the disparity in Cluster 1 was more obvious. The proportion of in-services in Cluster1, Cluster2, and Cluster 3 was higher than that of retired. Cluster 1, Cluster 2, and Cluster 3 had a higher proportion of Nuclear family types and a lower proportion of singleparent families. The proportion of the urban population in Cluster 1, Cluster2, and Cluster 3 was higher. The proportion of married and unmarried people was higher in Cluster 1 and Cluster3, and the proportion of married people was higher in Cluster 2. The proportion of childless people in Cluster 1, Cluster2, and Cluster 3 was higher, and the difference was even greater in Cluster 1. A higher percentage of cluster 1, Cluster 2 and Cluster 3 had one or two people living with them. The proportion of the population using public health insurance is higher in Cluster 1, Cluster 2 and Cluster 3. 
There were no chronic diseases in Cluster 1, Cluster2, and Cluster 3, but a high percentage of people with disabilities. Among Cluster 1, Cluster 2 and Cluster 3 , the proportion of people who had recently consumed alcohol was higher. 
Table 2

Demographic characteristics of each cluster [n (\%)].

\begin{tabular}{|c|c|c|c|c|}
\hline & Cluster 1 & Cluster 1 & Cluster 1 & P-value \\
\hline & Low risk & Low risk & Low risk & \\
\hline Gender & & & & $<0.001$ \\
\hline Man & $1330(49.6 \%)$ & $1846(40.2 \%)$ & 1857 (49.3\%) & \\
\hline Woman & 1349 (50.4\%) & $2743(59.8 \%)$ & 1906 (50.7\%) & \\
\hline Age & & & & $<0.001$ \\
\hline$\sim 18$ & $280(10.5 \%)$ & $433(9.4 \%)$ & $352(9.4 \%)$ & \\
\hline $19 \sim 45$ & 1766 (65.9\%) & $2532(55.2 \%)$ & 2303 (61.2\%) & \\
\hline $46 \sim 59$ & 502 (18.7\%) & 1025 (22.3\%) & 691 (18.4\%) & \\
\hline $60 \sim 75$ & $110(4.1 \%)$ & 445 (9.7\%) & $320(8.5 \%)$ & \\
\hline 76 90 & $17(0.6 \%)$ & $150(3.3 \%)$ & 93 (2.5\%) & \\
\hline $91 \sim$ & $4(0.1 \%)$ & $4(0.1 \%)$ & $4(0.1 \%)$ & \\
\hline Income & & & & $<0.001$ \\
\hline 3000 & 532 (19.9\%) & $1380(30.1 \%)$ & $1334(35.5 \%)$ & \\
\hline $3001 \sim 7500$ & 1299 (48.5\%) & $2294(50.0 \%)$ & $1732(46.0 \%)$ & \\
\hline $7501 \sim$ & 848 (31.7\%) & 915 (19.9\%) & 697 (18.5\%) & \\
\hline Hukou & & & & $<0.001$ \\
\hline Urban & 1787 (66.7\%) & 2567 (55.9\%) & 2006 (53.3\%) & \\
\hline Rural & 892 (33.3\%) & $2022(44.1 \%)$ & 1757 (46.7\%) & \\
\hline Politics & & & & $<0.001$ \\
\hline CPC & 749 (28.0\%) & 798 (17.4\%) & $574(15.3 \%)$ & \\
\hline Communist youth league & $862(32.2 \%)$ & $1138(24.8 \%)$ & $1056(28.1 \%)$ & \\
\hline Other parties & $965(36.0 \%)$ & $2433(53.0 \%)$ & $1918(51.0 \%)$ & \\
\hline Masses & $103(3.8 \%)$ & $220(4.8 \%)$ & $215(5.7 \%)$ & \\
\hline Education & & & & $<0.001$ \\
\hline Below secondary school & $26(1.0 \%)$ & $163(3.6 \%)$ & $189(5.0 \%)$ & \\
\hline Secondary Education & $272(10.2 \%)$ & $1139(24.8 \%)$ & $777(20.6 \%)$ & \\
\hline College and Bachelor & $424(15.8 \%)$ & $847(18.5 \%)$ & $707(18.8 \%)$ & \\
\hline Master and PhD & $1658(61.9 \%)$ & $2201(48.0 \%)$ & $1891(50.3 \%)$ & \\
\hline Below secondary school & $299(11.2 \%)$ & $239(5.2 \%)$ & $199(5.3 \%)$ & \\
\hline Work status & & & & $<0.001$ \\
\hline
\end{tabular}




\begin{tabular}{|c|c|c|c|c|}
\hline & Cluster 1 & Cluster 1 & Cluster 1 & P-value \\
\hline & Low risk & Low risk & Low risk & \\
\hline Working & $1297(48.4 \%)$ & 1953 (42.6\%) & $1387(36.9 \%)$ & \\
\hline Retired & $161(6.0 \%)$ & $438(9.5 \%)$ & $285(7.6 \%)$ & \\
\hline Student & $933(34.8 \%)$ & $1217(26.5 \%)$ & $1164(30.9 \%)$ & \\
\hline No fixed occupation & $288(10.8 \%)$ & $981(21.4 \%)$ & $927(24.6 \%)$ & \\
\hline Family type & & & & $<0.001$ \\
\hline Nuclear family & $1662(62.0 \%)$ & 2847 (62.0\%) & $2038(54.2 \%)$ & \\
\hline Conjugal family & $429(16.0 \%)$ & $625(13.6 \%)$ & 709 (18.8\%) & \\
\hline Backbone family & $251(9.4 \%)$ & $635(13.8 \%)$ & $459(12.2 \%)$ & \\
\hline Single-parent family & $75(2.8 \%)$ & $168(3.7 \%)$ & $175(4.7 \%)$ & \\
\hline Other & $262(9.8 \%)$ & $314(6.8 \%)$ & $382(10.2 \%)$ & \\
\hline Location recently & & & & 0.075 \\
\hline Eastern region & $1427(53.3 \%)$ & $2306(50.3 \%)$ & $1877(49.9 \%)$ & \\
\hline Central region & $658(24.6 \%)$ & $1196(26.1 \%)$ & $998(26.5 \%)$ & \\
\hline Western region & $593(22.1 \%)$ & 1087 (23.7\%) & $886(23.6 \%)$ & \\
\hline Residence & & & & $<0.001$ \\
\hline Urban & $2134(79.7 \%)$ & $3271(71.3 \%)$ & $2603(69.2 \%)$ & \\
\hline Rural & $545(20.3 \%)$ & $1318(28.7 \%)$ & $1160(30.8 \%)$ & \\
\hline Marriage & & & & $<0.001$ \\
\hline Unmarried & 1205 (45.0\%) & $1582(34.5 \%)$ & $1576(41.9 \%)$ & \\
\hline Married & $1421(53.0 \%)$ & $2803(61.1 \%)$ & $2002(53.2 \%)$ & \\
\hline Divorce & $43(1.6 \%)$ & $66(1.4 \%)$ & $98(2.6 \%)$ & \\
\hline Widowed & $10(0.4 \%)$ & $138(3.0 \%)$ & 87 (2.3\%) & \\
\hline Children & & & & $<0.001$ \\
\hline No & 1415 (52.8\%) & 1819 (39.6\%) & $1828(48.6 \%)$ & \\
\hline One & 772 (28.8\%) & 1350 (29.4\%) & 937 (24.9\%) & \\
\hline Two & $418(15.6 \%)$ & 1064 (23.2\%) & $752(20.0 \%)$ & \\
\hline Three or more & $74(2.8 \%)$ & $356(7.8 \%)$ & $246(6.5 \%)$ & \\
\hline Household & & & & $<0.001$ \\
\hline No & 267 (10.0\%) & $301(6.6 \%)$ & 495 (13.2\%) & \\
\hline One & $810(30.3 \%)$ & 1479 (32.3\%) & $1327(35.3 \%)$ & \\
\hline Two & 791 (29.6\%) & 1389 (30.3\%) & $963(25.6 \%)$ & \\
\hline
\end{tabular}




\begin{tabular}{|c|c|c|c|c|}
\hline & Cluster 1 & Cluster 1 & Cluster 1 & P-value \\
\hline & Low risk & Low risk & Low risk & \\
\hline Three & 440 (16.4\%) & 739 (16.1\%) & $507(13.5 \%)$ & \\
\hline Four & $150(5.6 \%)$ & $323(7.0 \%)$ & $214(5.7 \%)$ & \\
\hline Five or more & $217(8.1 \%)$ & $355(7.7 \%)$ & $254(6.8 \%)$ & \\
\hline Public insurance & & & & $<0.001$ \\
\hline No & $833(31.1 \%)$ & 1325 (28.9\%) & 779 (20.7\%) & \\
\hline Yes & $1846(68.9 \%)$ & $3264(71.1 \%)$ & $2984(79.3 \%)$ & \\
\hline Chronic disease & & & & $<0.001$ \\
\hline No & $2352(87.8 \%)$ & 3595 (78.3\%) & $3037(80.7 \%)$ & \\
\hline One & $242(9.0 \%)$ & $661(14.4 \%)$ & $479(12.7 \%)$ & \\
\hline Two or more & $85(3.2 \%)$ & $333(7.3 \%)$ & $247(6.6 \%)$ & \\
\hline Disability & & & & 0.001 \\
\hline No & $2603(97.2 \%)$ & $4464(97.3 \%)$ & 3617 (96.1\%) & \\
\hline Yes & $76(2.8 \%)$ & $125(2.7 \%)$ & $146(3.9 \%)$ & \\
\hline Drinking status & & & & $<0.001$ \\
\hline Yes, within 30 days & $1491(55.7 \%)$ & $2842(61.9 \%)$ & $2245(59.7 \%)$ & \\
\hline Yes, before 30 days & $342(12.8 \%)$ & $510(11.1 \%)$ & $456(12.1 \%)$ & \\
\hline No & 846 (31.6\%) & 1237 (27.0\%) & $1062(28.2 \%)$ & \\
\hline
\end{tabular}

Table3 describes the differences in the demographics and Characteristic Variables for smart home usage. The gender factor in the overall use has the remarkable difference, displays for the female overall use rate to be higher than the male. There were significant differences in age factors. The overall rate of using entertainment smart home was higher among 19-45-year-olds, and the rate of using smart home for functional and health was higher among 91-year-olds. The income factor has the remarkable difference, manifests for the income above 7500 high income crowd each kind of smart home use ratio to be high. There are significant differences in household factors, and the proportion of various kinds of smart home in rural household is high. There are significant differences in the political landscape, with a higher proportion of CPC smart homes being used. The educational factor has the remarkable difference, displays for the master degree above crowd to use each kind of intelligent home the proportion to be big. There were significant differences in the working environment, with a higher proportion of in-services using various types of smart home. There were significant differences in household type factors, with people with Nuclear family type using a higher proportion of different types of smart home. There is a significant difference between recreation and health in the factors of recent residence, which shows that the proportion of recreation is higher in the western region and health is higher in the Eastern Region. There are significant differences in the factors of residence, indicating that the proportion of urban population using various kinds of smart home will be higher. There were significant differences in factors related to marital status, which indicated that unmarried people had a higher overall utilization rate and a higher proportion of healthy smart homes, while divorced people used a higher proportion of functional smart homes. There was a significant difference in the number of children, as demonstrated by the higher overall utilization rate of one child and the higher utilization rate of recreational smart homes, and the higher proportion of functional and health analogs 
among the childless population. There are significant differences in the factors of public insurance, as a result of the high usage rate of various smart homes among the insured population. There were significant differences in the factors of chronic diseases, and the proportion of using various smart home without chronic diseases was higher. There was a significant difference in the factors of drinking, which showed that the proportion of using health smart homes was higher among the people who drank before 30 days. See Table S7 in the Supplementary Material for more details on demographic differences in overall smart home use. The analysis of demographic differences in users is detailed in Table S7 in Supplementary Material. 
Table 3

Demographic differences in utilization rate of smart home

\begin{tabular}{|c|c|c|c|c|c|c|c|c|}
\hline & \multicolumn{2}{|c|}{ Total smart home } & \multicolumn{2}{|c|}{$\begin{array}{l}\text { Entertainment smart } \\
\text { home }\end{array}$} & \multicolumn{2}{|c|}{$\begin{array}{l}\text { Functional smart } \\
\text { home }\end{array}$} & \multicolumn{2}{|c|}{ Health smart home } \\
\hline & $\begin{array}{l}\text { Utilization } \\
\text { rate }\end{array}$ & $\begin{array}{l}P \text { - } \\
\text { value }\end{array}$ & $\begin{array}{l}\text { Utilization } \\
\text { rate }\end{array}$ & $\begin{array}{l}P \text { - } \\
\text { value }\end{array}$ & $\begin{array}{l}\text { Utilization } \\
\text { rate }\end{array}$ & $\begin{array}{l}P- \\
\text { value }\end{array}$ & $\begin{array}{l}\text { Utilization } \\
\text { rate }\end{array}$ & $\begin{array}{l}P \text { - } \\
\text { value }\end{array}$ \\
\hline Gender & & $<0.001$ & & 0.303 & & 0.011 & & 0.089 \\
\hline Man & $78.96 \%$ & & $52.43 \%$ & & $65.25 \%$ & & $59.55 \%$ & \\
\hline Woman & $81.74 \%$ & & $51.45 \%$ & & $67.56 \%$ & & $61.14 \%$ & \\
\hline Age & & $<0.001$ & & $<0.001$ & & $<0.001$ & & $<0.001$ \\
\hline 18 & $82.07 \%$ & & $53.80 \%$ & & $64.69 \%$ & & $61.50 \%$ & \\
\hline 19 45 & $83.00 \%$ & & $54.13 \%$ & & $69.19 \%$ & & $64.78 \%$ & \\
\hline $46 \sim 59$ & $79.44 \%$ & & $51.04 \%$ & & $65.83 \%$ & & $57.66 \%$ & \\
\hline $60 \sim 75$ & $67.54 \%$ & & $40.46 \%$ & & $54.63 \%$ & & $41.37 \%$ & \\
\hline 76 90 & $61.92 \%$ & & $34.23 \%$ & & $50.38 \%$ & & $31.54 \%$ & \\
\hline $91 \sim$ & $83.33 \%$ & & $33.33 \%$ & & $91.67 \%$ & & $83.33 \%$ & \\
\hline Income & & $<0.001$ & & $<0.001$ & & $<0.001$ & & $<0.001$ \\
\hline 3000 & $72.03 \%$ & & $46.52 \%$ & & $56.75 \%$ & & $48.27 \%$ & \\
\hline $3001 \sim 7500$ & $82.85 \%$ & & $52.13 \%$ & & $68.19 \%$ & & $62.10 \%$ & \\
\hline $7501 \sim$ & $86.46 \%$ & & $58.50 \%$ & & $75.73 \%$ & & $72.76 \%$ & \\
\hline $\begin{array}{l}\text { Register } \\
\text { Residence }\end{array}$ & & $<0.001$ & & $<0.001$ & & $<0.001$ & & $<0.001$ \\
\hline Urban & $66.07 \%$ & & $42.77 \%$ & & $55.36 \%$ & & $52.49 \%$ & \\
\hline Rural & $83.19 \%$ & & $76.08 \%$ & & $96.03 \%$ & & $81.41 \%$ & \\
\hline Politics & & $<0.001$ & & $<0.001$ & & $<0.001$ & & $<0.001$ \\
\hline $\mathrm{CPC}$ & $83.97 \%$ & & $55.59 \%$ & & $72.14 \%$ & & $69.45 \%$ & \\
\hline $\begin{array}{l}\text { Communist youth } \\
\text { league }\end{array}$ & $82.62 \%$ & & $52.52 \%$ & & $66.92 \%$ & & $64.66 \%$ & \\
\hline Other parties & $77.82 \%$ & & $49.66 \%$ & & $63.54 \%$ & & $54.61 \%$ & \\
\hline Masses & $80.67 \%$ & & $55.95 \%$ & & $71.19 \%$ & & $57.99 \%$ & \\
\hline Education & & $<0.001$ & & $<0.001$ & & $<0.001$ & & $<0.001$ \\
\hline Illiteracy & $59.79 \%$ & & $36.24 \%$ & & $47.88 \%$ & & $30.95 \%$ & \\
\hline $\begin{array}{l}\text { Below secondary } \\
\text { school }\end{array}$ & $72.12 \%$ & & $48.03 \%$ & & $58.32 \%$ & & $45.29 \%$ & \\
\hline $\begin{array}{l}\text { Secondary } \\
\text { Education }\end{array}$ & $80.94 \%$ & & $52.22 \%$ & & $66.23 \%$ & & $58.70 \%$ & \\
\hline
\end{tabular}




\begin{tabular}{|c|c|c|c|c|c|c|c|c|}
\hline & \multicolumn{2}{|c|}{ Total smart home } & \multicolumn{2}{|c|}{$\begin{array}{l}\text { Entertainment smart } \\
\text { home }\end{array}$} & \multicolumn{2}{|c|}{$\begin{array}{l}\text { Functional smart } \\
\text { home }\end{array}$} & \multicolumn{2}{|c|}{ Health smart home } \\
\hline & $\begin{array}{l}\text { Utilization } \\
\text { rate }\end{array}$ & $\begin{array}{l}\mathrm{P} \text { - } \\
\text { value }\end{array}$ & $\begin{array}{l}\text { Utilization } \\
\text { rate }\end{array}$ & $\begin{array}{l}\mathrm{P} \text { - } \\
\text { value }\end{array}$ & $\begin{array}{l}\text { Utilization } \\
\text { rate }\end{array}$ & $\begin{array}{l}\mathrm{P} \text { - } \\
\text { value }\end{array}$ & $\begin{array}{l}\text { Utilization } \\
\text { rate }\end{array}$ & $\begin{array}{l}\mathrm{P} \text { - } \\
\text { value }\end{array}$ \\
\hline $\begin{array}{l}\text { College and } \\
\text { Bachelor }\end{array}$ & $84.12 \%$ & & $53.11 \%$ & & $69.76 \%$ & & $66.43 \%$ & \\
\hline Master and PhD & $86.16 \%$ & & $61.06 \%$ & & $75.71 \%$ & & $78.02 \%$ & \\
\hline Work status & & $<0.001$ & & $<0.001$ & & $<0.001$ & & $<0.001$ \\
\hline In-service & $84.49 \%$ & & $55.34 \%$ & & $71.71 \%$ & & $67.03 \%$ & \\
\hline Retired & $73.64 \%$ & & $44.12 \%$ & & $60.18 \%$ & & $49.55 \%$ & \\
\hline Student & $81.38 \%$ & & $51.81 \%$ & & $64.36 \%$ & & $62.40 \%$ & \\
\hline $\begin{array}{l}\text { No fixed } \\
\text { occupation }\end{array}$ & $73.36 \%$ & & $47.91 \%$ & & $61.29 \%$ & & $47.81 \%$ & \\
\hline Family type & & $<0.001$ & & $<0.001$ & & 0.004 & & $<0.001$ \\
\hline Nuclear family & $82.86 \%$ & & $53.75 \%$ & & $67.33 \%$ & & $62.78 \%$ & \\
\hline Conjugal family & $79.24 \%$ & & $51.79 \%$ & & $67.90 \%$ & & $61.26 \%$ & \\
\hline Backbone family & $74.87 \%$ & & $46.10 \%$ & & $63.64 \%$ & & $52.86 \%$ & \\
\hline $\begin{array}{l}\text { Single-parent } \\
\text { family }\end{array}$ & $75.36 \%$ & & $46.89 \%$ & & $61.24 \%$ & & $54.07 \%$ & \\
\hline Other & $76.51 \%$ & & $49.79 \%$ & & $64.61 \%$ & & $56.05 \%$ & \\
\hline Location recently & & 0.810 & & 0.002 & & 0.620 & & $<0.001$ \\
\hline Eastern region & $80.48 \%$ & & $50.45 \%$ & & $66.84 \%$ & & $61.93 \%$ & \\
\hline Central region & $80.79 \%$ & & $52.49 \%$ & & $66.48 \%$ & & $61.50 \%$ & \\
\hline Western region & $80.09 \%$ & & $54.48 \%$ & & $65.74 \%$ & & $55.85 \%$ & \\
\hline Residence & & $<0.001$ & & $<0.001$ & & $<0.001$ & & $<0.001$ \\
\hline Urban & $82.79 \%$ & & $54.05 \%$ & & $69.21 \%$ & & $65.21 \%$ & \\
\hline Rural & $74.33 \%$ & & $46.21 \%$ & & $59.35 \%$ & & $47.70 \%$ & \\
\hline Marriage & & $<0.001$ & & $<0.001$ & & $<0.001$ & & $<0.001$ \\
\hline Unmarried & $81.71 \%$ & & $53.24 \%$ & & $65.67 \%$ & & $63.37 \%$ & \\
\hline Married & $80.34 \%$ & & $51.56 \%$ & & $67.49 \%$ & & $59.33 \%$ & \\
\hline Divorce & $78.26 \%$ & & $49.28 \%$ & & $71.01 \%$ & & $57.97 \%$ & \\
\hline Widowed & $62.98 \%$ & & $38.30 \%$ & & $51.91 \%$ & & $36.17 \%$ & \\
\hline Children & & $<0.001$ & & $<0.001$ & & $<0.001$ & & $<0.001$ \\
\hline No & $82.00 \%$ & & $53.08 \%$ & & $66.77 \%$ & & $64.34 \%$ & \\
\hline One & $82.77 \%$ & & $51.98 \%$ & & $68.03 \%$ & & $64.11 \%$ & \\
\hline
\end{tabular}




\begin{tabular}{|c|c|c|c|c|c|c|c|c|}
\hline & \multicolumn{2}{|c|}{ Total smart home } & \multicolumn{2}{|c|}{$\begin{array}{l}\text { Entertainment smart } \\
\text { home }\end{array}$} & \multicolumn{2}{|c|}{$\begin{array}{l}\text { Functional smart } \\
\text { home }\end{array}$} & \multicolumn{2}{|c|}{ Health smart home } \\
\hline & $\begin{array}{l}\text { Utilization } \\
\text { rate }\end{array}$ & $\begin{array}{l}\mathrm{P} \text { - } \\
\text { value }\end{array}$ & $\begin{array}{l}\text { Utilization } \\
\text { rate }\end{array}$ & $\begin{array}{l}\mathrm{P} \text { - } \\
\text { value }\end{array}$ & $\begin{array}{l}\text { Utilization } \\
\text { rate }\end{array}$ & $\begin{array}{l}\mathrm{P} \text { - } \\
\text { value }\end{array}$ & $\begin{array}{l}\text { Utilization } \\
\text { rate }\end{array}$ & $\begin{array}{l}\mathrm{P} \text { - } \\
\text { value }\end{array}$ \\
\hline Two & $78.16 \%$ & & $51.34 \%$ & & $67.10 \%$ & & $53.54 \%$ & \\
\hline Three or more & $66.27 \%$ & & $44.53 \%$ & & $55.62 \%$ & & $36.98 \%$ & \\
\hline Household & & 0.088 & & 0.007 & & 0.016 & & 0.013 \\
\hline No & $81.75 \%$ & & $51.36 \%$ & & $69.24 \%$ & & $62.84 \%$ & \\
\hline One & $79.09 \%$ & & $49.64 \%$ & & $66.43 \%$ & & $58.35 \%$ & \\
\hline Two & $81.01 \%$ & & $52.85 \%$ & & $65.70 \%$ & & $62.17 \%$ & \\
\hline Three & $81.73 \%$ & & $53.08 \%$ & & $67.50 \%$ & & $60.44 \%$ & \\
\hline Four & $81.80 \%$ & & $56.62 \%$ & & $69.00 \%$ & & $61.57 \%$ & \\
\hline Five or more & $79.06 \%$ & & $52.42 \%$ & & $62.23 \%$ & & $58.72 \%$ & \\
\hline Public insurance & & $<0.001$ & & 0.004 & & $<0.001$ & & $<0.001$ \\
\hline No & $78.46 \%$ & & $49.46 \%$ & & $62.82 \%$ & & $55.40 \%$ & \\
\hline Yes & $82.51 \%$ & & $54.30 \%$ & & $70.13 \%$ & & $65.35 \%$ & \\
\hline Chronic disease & & $<0.001$ & & $<0.001$ & & $<0.001$ & & $<0.001$ \\
\hline No & $81.81 \%$ & & $52.77 \%$ & & $67.65 \%$ & & $62.21 \%$ & \\
\hline One & $75.33 \%$ & & $47.83 \%$ & & $60.71 \%$ & & $53.11 \%$ & \\
\hline Two or more & $73.08 \%$ & & $48.57 \%$ & & $63.01 \%$ & & $51.28 \%$ & \\
\hline Disability & & 0.003 & & 0.321 & & 0.112 & & 0.038 \\
\hline No & $80.67 \%$ & & $51.98 \%$ & & $66.63 \%$ & & $60.59 \%$ & \\
\hline Yes & $74.35 \%$ & & $49.28 \%$ & & $62.54 \%$ & & $55.04 \%$ & \\
\hline Drinking status & & 0.503 & & 0.066 & & 0.939 & & $<0.001$ \\
\hline Within 30 days & $80.13 \%$ & & $50.99 \%$ & & $66.37 \%$ & & $58.82 \%$ & \\
\hline Before 30 days & $81.35 \%$ & & $53.06 \%$ & & $66.67 \%$ & & $62.39 \%$ & \\
\hline No & $74.44 \%$ & & $49.11 \%$ & & $61.43 \%$ & & $57.95 \%$ & \\
\hline
\end{tabular}

Table 4 showed that there were significant differences among the three groups in the needs of 23 smart homes in three categories. Among them, the low risk group had higher demand for smart homes, especially functional homes, with a utilization rate of $77.42 \%$. It was much higher than that in the middle risk groups and high risk groups. Except that the demand for entertainment smart homes in the medium-risk groups was higher than that in the high risk group, the demand for functional and health smart home was lower than that in the high risk group. For the entertainment class, smart TV had the highest utilization rate, while VR glasses and body sensing cars had a lower utilization rate. For the functional class, the utilization rates of smart washing machines and smart air conditioners were high, while the utilization rates of electric current, smart clothes changers, smart mosquito reply, and smart robots were low. For 
healthsmart home, sports brace, body fat scale, and air purifier were used more frequently, while temperature and humidity sensor, danger button, smoke transmitter, and smart medicine cabinet were used less frequently. 
Table 4

The utilization rate of smart home for each cluster [n (\%)].

\begin{tabular}{|lllll|}
\hline & Cluster 1 & Cluster 2 & Cluster 3 & P-value \\
\cline { 2 - 5 } & Low risk & Middle risk & High risk & \\
\hline $\mathrm{n}$ & 2679 & 4589 & 3763 & \\
\hline Total smart home & $2484(92.72 \%)$ & $3749(81.70 \%)$ & $3083(81.93 \%)$ & $<0.001$ \\
\hline Entertainment smart home & $1636(61.07 \%)$ & $2364(51.51 \%)$ & $1725(45.84 \%)$ & $<0.001$ \\
\hline Smart TV & $1225(45.73 \%)$ & $1997(43.52 \%)$ & $1256(33.38 \%)$ & $<0.001$ \\
\hline VR glasses & $258(9.63 \%)$ & $125(2.72 \%)$ & $252(6.70 \%)$ & $<0.001$ \\
\hline Body sensing car & $220(8.21 \%)$ & $93(2.03 \%)$ & $201(5.34 \%)$ & $<0.001$ \\
\hline Smart speaker & $681(25.42 \%)$ & $706(15.38 \%)$ & $558(14.83 \%)$ & $<0.001$ \\
\hline Functional smart home & $2074(77.42 \%)$ & $2857(62.26 \%)$ & $2405(63.91 \%)$ & $<0.001$ \\
\hline Smart robot & $333(12.43 \%)$ & $241(5.25 \%)$ & $308(8.18 \%)$ & $<0.001$ \\
\hline Smart lighting & $571(21.31 \%)$ & $544(11.85 \%)$ & $537(14.27 \%)$ & $<0.001$ \\
\hline Smart washing machine & $1009(37.66 \%)$ & $1611(35.11 \%)$ & $997(26.49 \%)$ & $<0.001$ \\
\hline Smart switch & $545(20.34 \%)$ & $521(11.35 \%)$ & $529(14.06 \%)$ & $<0.001$ \\
\hline Smart door lock & $570(21.28 \%)$ & $551(12.01 \%)$ & $530(14.08 \%)$ & $<0.001$ \\
\hline Smart toilet & $443(16.54 \%)$ & $469(10.22 \%)$ & $379(10.07 \%)$ & $<0.001$ \\
\hline Smart mosquito repellent & $338(12.62 \%)$ & $239(5.21 \%)$ & $322(8.56 \%)$ & $<0.001$ \\
\hline Electric curtain & $312(11.65 \%)$ & $162(3.53 \%)$ & $292(7.76 \%)$ & $<0.001$ \\
\hline Smart air conditioner & $963(35.95 \%)$ & $1337(29.13 \%)$ & $926(24.61 \%)$ & $<0.001$ \\
\hline Smart clothes hanger & $343(12.80 \%)$ & $293(6.38 \%)$ & $331(8.80 \%)$ & $<0.001$ \\
\hline Smart monitoring & $417(15.57 \%)$ & $400(8.72 \%)$ & $416(11.06 \%)$ & $<0.001$ \\
\hline Health smart home & $2018(75.33 \%)$ & $2531(55.15 \%)$ & $2115(56.21 \%)$ & $<0.001$ \\
\hline Sports bracelet & $999(37.29 \%)$ & $1124(24.49 \%)$ & $859(22.83 \%)$ & $<0.001$ \\
\hline Temperature and humidity sensor & $272(10.15 \%)$ & $170(3.70 \%)$ & $261(6.94 \%)$ & $<0.001$ \\
\hline Smart socket & $454(16.95 \%)$ & $392(8.54 \%)$ & $455(12.09 \%)$ & $<0.001$ \\
\hline Danger button & $245(9.15 \%)$ & $131(2.85 \%)$ & $262(6.96 \%)$ & $<0.001$ \\
\hline Smoke transducer & $261(9.74 \%)$ & $231(5.03 \%)$ & $262(6.96 \%)$ & $<0.001$ \\
\hline Body fat scale & $994(37.10 \%)$ & $1291(28.13 \%)$ & $853(22.67 \%)$ & $<0.001$ \\
\hline Air purifier & $719(26.84 \%)$ & $646(14.08 \%)$ & $520(13.82 \%)$ & $<0.001$ \\
\hline Smart medicine cabinet & $225(8.40 \%)$ & $104(2.27 \%)$ & $222(5.90 \%)$ & $<0.001$ \\
\hline
\end{tabular}

\section{Subgroup analysis}


According to Table 5, there were significant differences in the demand for smart homes between urban and rural

populations. The urban population accounts for more than $70 \%$, while the rural population accounts for less than $30 \%$. This difference was caused by the differences in urban and rural economy, urban and rural education, the actual use place of smart home, and the practicability of the smart home. 
Table 5

Residence, gender, and age Subgroup analysis of smart home utilization rate.

\begin{tabular}{|c|c|c|c|c|c|c|c|c|c|c|}
\hline \multirow[t]{2}{*}{ Categories/definition } & \multicolumn{2}{|c|}{ Residence(\%) } & \multirow{2}{*}{$\begin{array}{l}P \text { - } \\
\text { value }\end{array}$} & \multicolumn{2}{|c|}{ Gender(\%) } & \multirow{2}{*}{$\begin{array}{l}\mathrm{P}- \\
\text { value }\end{array}$} & \multicolumn{3}{|l|}{ Age(\%) } & \multirow{2}{*}{$\begin{array}{l}\mathrm{P} \text { - } \\
\text { value }\end{array}$} \\
\hline & Urban & Rural & & Male & Female & & 45 59 & $60 \sim 75$ & $76 \sim$ & \\
\hline \multicolumn{11}{|l|}{$\begin{array}{l}\text { Entertainment smart } \\
\text { home }\end{array}$} \\
\hline Smart speaker & $78 \%$ & $22 \%$ & $<0.001$ & $54 \%$ & $46 \%$ & 0.073 & $75 \%$ & $20 \%$ & $5 \%$ & $<0.001$ \\
\hline VR glasses & $79 \%$ & $21 \%$ & $<0.001$ & $61 \%$ & $39 \%$ & 0.013 & $76 \%$ & $20 \%$ & $4 \%$ & $<0.001$ \\
\hline Body sensing car & $74 \%$ & $26 \%$ & $<0.001$ & $61 \%$ & $39 \%$ & 0.024 & $58 \%$ & $30 \%$ & $12 \%$ & $<0.001$ \\
\hline Smart TV & $72 \%$ & $28 \%$ & $<0.001$ & $53 \%$ & $47 \%$ & 0.016 & $71 \%$ & $23 \%$ & $6 \%$ & $<0.001$ \\
\hline \multicolumn{11}{|l|}{$\begin{array}{l}\text { Functional smart } \\
\text { home }\end{array}$} \\
\hline Smart robot & $80 \%$ & $20 \%$ & $<0.001$ & $55 \%$ & $45 \%$ & 0.120 & $72 \%$ & $24 \%$ & $3 \%$ & $<0.001$ \\
\hline Smart air conditioner & $73 \%$ & $27 \%$ & $<0.001$ & $50 \%$ & $50 \%$ & 0.844 & $72 \%$ & $23 \%$ & $5 \%$ & $<0.001$ \\
\hline Smart lighting & $71 \%$ & $29 \%$ & $<0.001$ & $49 \%$ & $61 \%$ & 0.779 & $70 \%$ & $22 \%$ & $8 \%$ & $<0.001$ \\
\hline $\begin{array}{l}\text { Smart washing } \\
\text { machine }\end{array}$ & $73 \%$ & $27 \%$ & $<0.001$ & $49 \%$ & $61 \%$ & 0.477 & $73 \%$ & $21 \%$ & $5 \%$ & $<0.001$ \\
\hline Smart switch & $71 \%$ & $29 \%$ & $<0.001$ & $50 \%$ & $50 \%$ & 0.961 & $69 \%$ & $23 \%$ & $9 \%$ & $<0.001$ \\
\hline Smart door lock & $82 \%$ & $18 \%$ & $<0.001$ & $50 \%$ & $50 \%$ & 0.882 & $78 \%$ & $18 \%$ & $5 \%$ & $<0.001$ \\
\hline Smart toilet & $85 \%$ & $15 \%$ & $<0.001$ & $49 \%$ & $51 \%$ & 0.748 & $71 \%$ & $23 \%$ & $6 \%$ & $<0.001$ \\
\hline $\begin{array}{l}\text { Smart mosquito } \\
\text { repellent }\end{array}$ & $75 \%$ & $25 \%$ & $<0.001$ & $51 \%$ & $29 \%$ & 0.730 & $70 \%$ & $27 \%$ & $3 \%$ & $<0.001$ \\
\hline $\begin{array}{l}\text { Smart clothes } \\
\text { hanger }\end{array}$ & $80 \%$ & $20 \%$ & $<0.001$ & $43 \%$ & $57 \%$ & 0.021 & $70 \%$ & $25 \%$ & $5 \%$ & $<0.001$ \\
\hline Electric curtain & $75 \%$ & $25 \%$ & $<0.001$ & $55 \%$ & $45 \%$ & 0.120 & $66 \%$ & $26 \%$ & $8 \%$ & $<0.001$ \\
\hline Smart monitoring & $66 \%$ & $34 \%$ & $<0.001$ & $51 \%$ & $49 \%$ & 0.621 & $63 \%$ & $29 \%$ & $9 \%$ & $<0.001$ \\
\hline \multicolumn{11}{|l|}{ Healthsmart home } \\
\hline Smart bracelet & $80 \%$ & $20 \%$ & $<0.001$ & $55 \%$ & $45 \%$ & 0.018 & $78 \%$ & $17 \%$ & $6 \%$ & $<0.001$ \\
\hline Body fat scale & $78 \%$ & $22 \%$ & $<0.001$ & $49 \%$ & $51 \%$ & 0.438 & $75 \%$ & $20 \%$ & $5 \%$ & $<0.001$ \\
\hline $\begin{array}{l}\text { Smart medicine } \\
\text { cabinet }\end{array}$ & $80 \%$ & $20 \%$ & $<0.001$ & $61 \%$ & $39 \%$ & 0.018 & $66 \%$ & $29 \%$ & $6 \%$ & $<0.001$ \\
\hline Smart socket & $70 \%$ & $30 \%$ & $<0.001$ & $56 \%$ & $44 \%$ & 0.036 & $74 \%$ & $22 \%$ & $5 \%$ & $<0.001$ \\
\hline $\begin{array}{l}\text { Temperature and } \\
\text { humidity sensor }\end{array}$ & $79 \%$ & $21 \%$ & $<0.001$ & $59 \%$ & $41 \%$ & 0.017 & $70 \%$ & $28 \%$ & $2 \%$ & $<0.001$ \\
\hline Danger button & $73 \%$ & $27 \%$ & $<0.001$ & $52 \%$ & $48 \%$ & 0.580 & $59 \%$ & $30 \%$ & $11 \%$ & $<0.001$ \\
\hline Smoke transducer & $83 \%$ & $17 \%$ & $<0.001$ & $53 \%$ & $47 \%$ & 0.346 & $63 \%$ & $30 \%$ & $7 \%$ & $<0.001$ \\
\hline Air purifier & $85 \%$ & $15 \%$ & $<0.001$ & $50 \%$ & $50 \%$ & 0.860 & $71 \%$ & $25 \%$ & $4 \%$ & $<0.001$ \\
\hline
\end{tabular}


There were significant differences in the demand for smart homes among people of different ages. The middle-aged (45 49 years old) account for more than 50\%, while the elderly (76 years old) were generally less than 10\%. This difference was caused by educational level, cognitive ability, physical action, and economic status

There were gender differences in the needs of VR glasses, body-sensing cars, smart TV, smart brace, smart medicine cabinet, smart socket, temperature, and humidity sensors, and the demand of men was higher than that of women. This difference was caused by physiological differences, family structure, and income differences. At the same time, gender differences also had differences in the demand for smart clothes changers, which shows that the demand of women was higher than that of men. The reason for this difference is that women pursue fashion and appearance more than men do. And women's clothing is more expensive than men's, so women will pay attention to the protection and proper custody of clothing.

\section{Discussion}

In the context of the COVID-19 pandemic, the importance and convenience of digital health are becoming more and more prominent[29, 30], with telemedicine enabling people to have medical consultations at home and avoid infections, and many countries and regions are actively promoting the development of digital health [31, 32]. Identifying the needs of different groups of people for smart homes is important to promote the implementation of digital health strategies, and we conducted a cluster analysis of the population based on health-related risks, divided into three groups: the low risk group, the medium-risk group, and the high risk group, and confirmed the differences in the needs of different groups of people for smart homes through research and analysis.

The usage rate of smart homes for the low health-related risk group was $86.97 \%$, the usage rate for the medium healthrelated risk group was $79.23 \%$ and the usage rate for the high health-related risk group was $77.36 \%$, the lower the health-related risk the better the usage of the smart home. The low health-related risk group had higher health literacy and chronic disease self-behavior management had a stronger health mindset, were better able to self-manage their diseases [33,34], and were more likely to use smart homes for health management. In addition to this, the population of the low health-related risks group had the best media use among those, with greater information exposure, and more likely to learn about smart home-related information. In addition to these factors, sociodemographic characteristics also had an impact on smart home use in the three groups

The age distribution of the low risk group was younger than the other two groups, with younger people using smart homes better than older people, and Alhuwail D's study also indicated that younger people used smart devices more than older people [35]. Our analysis suggests that age affects smart home use in four main ways. Firstly, consumer perceptions are different; while older people show positive attitudes during the experience of the entertainment smart home - VR glasses - they do not have a strong desire to buy them, believing that smart homes are unnecessary in their lives, while younger people associate the experience more with the content being fun [36]. Secondly, the prevalence of chronic diseases is higher among the elderly [37-39], and studies have shown that three-quarters of the elderly in China suffer from at least one chronic disease [40], and health a smart homes can help them with daily check-ups of diseases and daily behavior management [41-43]. The China Quality of Life Development Report for the Elderly (2019) shows that about $29.6 \%$ of the elderly in China have not attended school, $41.5 \%$ have a primary school education, and $25.8 \%$ have middle and high school education. It can be seen that the literacy level of older people in China is relatively low [44], and the low level of education limits the use of smart products by older people. Finally, due to the deterioration of physical functions, the elderly have difficulty in understanding the operation of smart homes and are worried about not being able to use them independently without help $[45,46]$. 
The low risk group has the highest proportion of high-income people, and income is one of the influencing factors for smart home usage. Smart home products have higher technical requirements for research and development, require a higher level of R\&D talents, and have high manufacturing costs. Small companies also find it difficult to enter this industry due to technical and financial problems, making it difficult to achieve scale effects, which leads to the problem of high prices of smart home products, and many users also indicated during the survey that purchase cost is one of the main considerations [47].

The low risk group had a larger urban population, and place of residence was also a significant influencing factor on smart home use, with urban use better than rural. According to the survey, $84.2 \%$ of urban students in the Washington State school district reported being able to use reliable broadband to watch instructional videos, while only $67.5 \%$ of rural areas agreed [48]. In China, the Internet gap between urban and rural areas is gradually decreasing, but there is still a $24.1 \%$ difference in penetration rates [49]. Smart homes are built on the internet, rural Internet infrastructure is weaker than urban areas, and the digital divide is a barrier to the spread of digital health in rural areas [50,51], which is one of the reasons for the low usage of smart homes in rural areas. In addition to this, there are differences in access to health information between rural and urban residents, with rural residents having less access to health related information from sources such as specialists, magazines and less frequent use of search engines than urban residents [52], which may contribute to rural residents not knowing enough about digital health and smart homes.

Although there are many differences in the demand for smart homes among different health-related risk groups, they also show similarities: men have a significantly higher purchase rate for VR glasses, body cars, smart bracelets, smart pillboxes, smart sockets, and temperature and humidity sensors than women, but women have a significantly higher usage rate for smart drying racks than men. This is mainly determined by lifestyle, income, and subjective willingness. Currently, men generally have higher incomes than the income of women [53,54], which determines that men have stronger purchasing power for higher-priced smart homes. Secondly, men and women have different household lifestyles; women take on more household chores $[55,56]$ and maybe more interested in smart drying racks related to household chores, while men have more leisure time at home and purchase more entertainment products. In addition, research has shown significant differences in the technology acceptance between men and women, with men showing a stronger intention to use technology $[57,58]$, while women are more interested in fashion products during consumption [59] and maybe more interested in daily protection of clothing closely related to fashion.

Looking at the three broad smart home categories, smart TVs have the highest usage rate in the category of entertainment, with VR glasses and body sense cars having lower usage rates. This is related to the high frequency of use and usefulness of TVs as traditional homes [60], while VR glasses and body cars may show lower usage because our sample includes middle aged and elderly people, who are limited by their age and physical mobility [61] to use such exercise products. In the category of functional, smart washing machines and smart air conditioners were used more frequently, while electric curtains, smart hangers, smart mosquito repellents and smart robots were used less frequently. This is related to the influence of the early use of washing machines and air conditioners that are widely used and highly practical, while electric curtains, smart drying racks and mosquito extinguishers are less practical and costeffective, and smart robots are narrowly used, expensive and technically immature, with most of the experiencers expressing a neutral attitude[62].In the health category, the usage rate of sports bracelets, body fat scales and air purifiers were high, while the usage rate of temperature and humidity sensors, hazard buttons, smoke sensors and smart medicine cabinets was low. This is related to the development of supporting facilities such as the Internet, the popularity of sports bracelets, body fat scales and air purifiers, and their low prices. The rest of the products are not as popular, cost-effective and practical, and have fewer manufacturers. We could not find any information about these products on the official websites of the larger Chinese smart home manufacturers, Xiaomi and Huawei. 
Implementing a digital health strategy requires a concerted effort by product manufacturers and the government. As older people consume products with greater consideration for ease of use and practicality, manufacturers should pay more attention to the older market and simplify the steps and the interface design of their products. Studies have shown that user involvement in the product design can effectively improve the quality, relevance and prevalence of work $[63,64]$, and companies can recruit volunteers to participate in the design process as appropriate to the actual situation. Health products are of importance for aging [42], but the current smart home market has a small range of such products, so manufacturers need to implement the concept of digital health and increase the development, production and promotion of such products. Because of the poor usage of smart homes among the elderly, low-income groups, rural residents and women, manufacturers should pay more attention to the positive and negative factors influencing their purchases and broaden the market for their products.

The high production costs of companies lead to the high pricing of products, which is one of the major obstacles to people using smart homes. The government can enhance policy guidance to attract investors and capital into the smart home market and reduce the production pressure on enterprises. In addition, the government should also encourage enterprises to invest in technology research and development to break through existing technical difficulties, thereby reducing the difficulty of product production and achieving lower product prices. Secondly, because there is also no unified industry-standard specification for smart homes in China [3], while different companies have different product compatibility [65], leading to the problem that elderly users feel more difficult to use in the process. The relevant authorities should formulate industry standards to address this issue and solve the problem of different product compatibility. Finally, the government also needs to pay attention to strengthening the construction of residents' health knowledge system, raising their health awareness, reducing their health-related risks, improving their ability and awareness of using technology for health management, and fully implementing digital health strategies to improve the quality of their healthy lives and achieve health for all.

Our study clustered the five influencing factors of health-related risk: family health, perceived social support, health literacy, chronic disease behavior management and media exposure into three groups: the low risk group, the mediumrisk group, and the high risk group, which contributed to a new way of segmentation. In addition to this, the relationship between health-related risk and smart home use has never been looked at in previous studies, but our study demonstrates that smart home use differs between health-related risk groups, with the low health-related risk groups showing better overall smart home use, and confirms that people currently prefer functional smart home products and that low health-related risk groups are also concerned about health products. This suggests that our research hypothesis that different levels of health-related risk influence smart home use are valid. These findings provide important new insights that have implications for the development of the smart home industry and the implementation of digital health strategies.

However, due to limitations in research experience and resources, our study also has certain limitations. Our survey was conducted through respondents retrospectively completing a questionnaire, which may be subject to recall bias.

Secondly, our study was a cross-sectional survey and was unable to demonstrate a causal relationship between healthrelated risks and smart home use, which could be explored in future studies through longitudinal research. Finally, we analyzed health-related risk through five dimensions: family health, perceived social support, health literacy, chronic disease behavior management, and media exposure, possibly ignoring the effect of other variables on health-related risk.

\section{Abbreviations}

HLS: Health Literacy Scale 
PSSS: Perceived Social Support Scale

FLS: Family Health Score

Self-management: chronic disease self-behavioral management

DEXA囚X-ray absorptiometry

SHUヌSmart Home Use

CDSMS $₫$ Chronic Disease Self-management Study Measure

FHS-SF『Family Health Scale-Short Form

HLS-SF12ðShort-Form Health Literacy Instrument

\section{Declarations}

\section{Competing interests}

The authors have no conflicts of interest to declare.

\section{Availability of data and materials}

The datasets supporting the conclusions of this article are included within the article and its additional files. All raw data can be obtained by sending an email to the corresponding author.

\section{Authors' Contributions}

HFY, WYB, YJ, LSW, and CJY participated in the conception and design of the study. WYB, DYQ, ZLP, CJX, and SXY completed the data collection. YJ, LLH, WFJ, KYF, and YSPJTES completed the collation of the data. YJ, CKE, and XJY completed the data analysis and wrote the first draft of the manuscript. CJY, HFY, and LSW contributed to supervising the data analysis and writing the manuscript. All authors contributed to the revision of the article and approved the final draft submitted.

\section{Ethics approval and consent to participate}

This study was reviewed by the Ethics Committee of Jinan University and written informed consent was required from all participants. The ethical approval number is JNUKY-2021-018. The study was conducted in accordance with the Declaration of Helsinki of the World Medical Association.

\section{Consent for publication}

Not applicable.

Funding 
This work was supported by the Medical Scientific Research Foundation of Guangdong Province (A2020420), the 13th Five-Year Plan of Guangdong Province for Philosophy and Social Sciences (GD20XGL42) and the Guangzhou Science and Technology Plan Project (202103000037). The funders had no role in the study design, data collection, data analysis, data interpretation and report writing. The corresponding author has full access to all data in the study and is ultimately responsible for the decision to submit for publication.

\section{References}

1. Opinions of the State Council on the Implementation of Health China Action (Guo Fa [2019] No. 13)_Government Information Disclos. http://www.gov.cn/zhengce/content/2019-07/15/content_5409492.htm. Accessed 11 October 2021.

2. strategy on digital health 2020-2025. https://www.who.int/publications/i/item/9789240020924. Accessed 11 October 2021.

3. Zhang Q, Li M, Wu Y: Smart home for elderly care: development and challenges in China. BMC GERIATR 2020, 20(1):318.

4. Yang T, Qiao Y, Xiang S, Li W, Gan Y, Chen Y: Work stress and the risk of cancer: A meta-analysis of observational studies. INT J CANCER 2019, 144(10):2390-2400.

5. van der Gronde T, Los L, Herremans A, Oosting R, Zorzanelli R, Pieters T: Toward a New Model of Understanding, Preventing, and Treating Adolescent Depression Focusing on Exhaustion and Stress. FRONT PSYCHIATRY 2020, 11.

6. Li C, Fahmy A, Li S, Sienz J: An Enhanced Robot Massage System in Smart Homes Using Force Sensing and a Dynamic Movement Primitive. FRONT NEUROROBOTICS 2020, 14.

7. Mayer P, Guldenpfennig F, Panek P: Towards Smart Adaptive Care Toilets. Stud Health Technol Inform 2019, 260:9-16.

8. Kim D, Chang C, Margrett J: Understanding Older Adults' Perception and Usage of Indoor Lighting in Independent Senior Living. HERD 2021, 14(3):215-228.

9. Tan SS, Fierloos IN, Zhang X, Koppelaar E, Alhambra-Borras T, Rentoumis T, Williams G, Rukavina T, van Staveren $\mathrm{R}$, Garces-Ferrer $\mathrm{J}$ et al: The Association between Loneliness and Health Related Quality of Life (HR-QoL) among Community-Dwelling Older Citizens. INT J ENV RES PUB HE 2020, 17(2).

10. Liu Y, Tamura R, Song Y: Constructing a Smart Home for Future Elders toward All-around Happiness: Taking Connectivity as the Core Element. APPL SCI-BASEL 2020, 10(16).

11. Smith E, Sumner P, Hedge C, Powell G: Smart speaker devices can improve speech intelligibility in adults with intellectual disability. INT J LANG COMM DIS 2021, 56(3):583-593.

12. Tasse MJ, Wagner JB, Kim M: Using technology and remote support services to promote independent living of adults with intellectual disability and related developmental disabilities. Journal of applied research in intellectual disabilities: JARID 2020, 33(3):640-647.

13. Fang EF, Xie C, Schenkel JA, Wu C, Long Q, Cui H, Aman Y, Frank J, Liao J, Zou H et al: A research agenda for ageing in China in the 21st century (2nd edition): Focusing on basic and translational research, long-term care, policy and social networks. AGEING RES REV 2020, 64:101174.

14. Internet Society of China-2021 China Internet Conference I $\square$ China Internet Development Report (2021) 『released in Beijing. https://www.isc.org.cn/zxzx/xhdt/listinfo-40203.html. Accessed 11 October 2021.

15. Frija-Masson J, Mullaert J, Vidal-Petiot E, Pons-Kerjean N, Flamant M, D'Ortho MP: Accuracy of Smart Scales on Weight and Body Composition: Observational Study. JMIR MHEALTH UHEALTH2021, 9(4):e22487. 
16. Zhao X, Zhu Z, Liu M, Zhao C, Zhao Y, Pan J, Wang Z, Wu C: A Smart Robotic Walker With Intelligent CloseProximity Interaction Capabilities for Elderly Mobility Safety. FRONT NEUROROBOTICS 2020, 14.

17. Arthanat S, Wilcox J, Macuch M: Profiles and Predictors of Smart Home Technology Adoption by Older Adults. OTJR (Thorofare N J) 2019, 39(4):247-256.

18. Jachan DE, Muller-Werdan U, Lahmann NA, Strube-Lahmann S: Smart@home - supporting safety and mobility of elderly and care dependent people in their own homes through the use of technical assistance systems and conventional mobility supporting tools: a cross-sectional survey. BMC GERIATR 2021, 21(1):205.

19. Sarla E, Lambrinou E, Galanis P, Kalokairinou A, Sourtzi P: Factors That Influence the Relationship Between Social Support and Health-Related Quality of Life of Older People Living in the Community. Gerontol Geriatr Med 2020, 6:598977678.

20. Long KQ, Thinh OP, Thao T, Van Huy N, Lan V, Mai VQ, Van Minh H: Relationship between family functioning and health-related quality of life among methadone maintenance patients: a Bayesian approach. QUAL LIFE RES 2020, 29(12):3333-3342.

21. Nguyen HC, Nguyen MH, Do BN, Tran CQ, Nguyen T, Pham KM, Pham LV, Tran KV, Duong TT, Tran TV et al: People with Suspected COVID-19 Symptoms Were More Likely Depressed and Had Lower Health-Related Quality of Life: The Potential Benefit of Health Literacy. J CLIN MED 2020, 9(4).

22. Ang S, Lim E, Malhotra R: Health-Related Difficulty in Internet Use Among Older Adults: Correlates and Mediation of Its Association With Quality of Life Through Social Support Networks. GERONTOLOGIST 2021, 61(5):693-702.

23. Wu H, Han S, Zhang G, Wu W, Tang N: Health-related quality of life and determinants in North-China urban community residents. Health Qual Life Outcomes 2020, 18(1):280.

24. Blumenthal JA, Burg MM, Barefoot J, Williams RB, Haney T, Zimet G: Social support, type A behavior, and coronary artery disease. PSYCHOSOM MED 1987, 49(4):331-340.

25. Crandall A, Weiss-Laxer NS, Broadbent E, Holmes EK, Magnusson BM, Okano L, Berge JM, Barnes MD, Hanson CL, Jones BL et al: The Family Health Scale: Reliability and Validity of a Short- and Long-Form. Front Public Health 2020, 8:587125.

26. Duong TV, Aringazina A, Kayupova G, Nurjanah, Pham TV, Pham KM, Truong TQ, Nguyen KT, Oo WM, Su TT et al: Development and Validation of a New Short-Form Health Literacy Instrument (HLS-SF12) for the General Public in Six Asian Countries. Health Lit Res Pract 2019, 3(2):e91-e102.

27. Lorig KR, Sobel DS, Stewart AL, Brown BJ, Bandura A, Ritter P, Gonzalez VM, Laurent DD, Holman HR: Evidence suggesting that a chronic disease self-management program can improve health status while reducing hospitalization: a randomized trial. MED CARE 1999, 37(1):5-14.

28. Lorig KR, Sobel DS, Ritter PL, Laurent D, Hobbs M: Effect of a self-management program on patients with chronic disease. Eff Clin Pract 2001, 4(6):256-262.

29. Fagherazzi G, Goetzinger C, Rashid MA, Aguayo GA, Huiart L: Digital Health Strategies to Fight COVID-19 Worldwide: Challenges, Recommendations, and a Call for Papers. J MED INTERNET RES 2020, 22(6).

30. Whitelaw S, Mamas MA, Topol E, Van Spall H: Applications of digital technology in COVID-19 pandemic planning and response. Lancet Digit Health 2020, 2(8):e435-e440.

31. Cohen IG, Evgeniou T, Gerke S, Minssen T: The European artificial intelligence strategy: implications and challenges for digital health. Lancet Digit Health 2020, 2(7):e376-e379.

32. Rizzato LD, Pedernera FA, Lopez E, Speranza CD, Guevel C, Maid JJ, Mac CP, Rolandi F, Ayala F, Abadie DA et al: Argentinian Digital Health Strategy. Stud Health Technol Inform 2020, 270:818-822. 
33. Papadakos JK, Hasan SM, Barnsley J, Berta W, Fazelzad R, Papadakos CJ, Giuliani ME, Howell D: Health literacy and cancer self-management behaviors: A scoping review. CANCER-AM CANCER SOC 2018, 124(21):4202-4210.

34. Clarke N, Dunne S, Coffey L, Sharp L, Desmond D, O'Conner J, O'Sullivan E, Timon C, Cullen C, Gallagher P: Health literacy impacts self-management, quality of life and fear of recurrence in head and neck cancer survivors. $J$ CANCER SURVIV 2021, 15(6):855-865.

35. Jaana M, Pare G: Comparison of Mobile Health Technology Use for Self-Tracking Between Older Adults and the General Adult Population in Canada: Cross-Sectional Survey. JMIR MHEALTH UHEALTH 2020, 8(11):e24718.

36. Liu Q, Wang Y, Tang Q, Liu Z: Do You Feel the Same as I Do? Differences in Virtual Reality Technology Experience and Acceptance Between Elderly Adults and College Students. FRONT PSYCHOL 2020, 11.

37. Zhao C, Wong L, Zhu Q, Yang H: Prevalence and correlates of chronic diseases in an elderly population: A community-based survey in Haikou. PLOS ONE 2018, 13(6).

38. Lyu J, Zhang W, Li W, Wang S, Zhang J: Epidemic of chronic diseases and the related healthy lifestyle interventions in rural areas of Shandong Province, China. BMC PUBLIC HEALTH2020, 20(1):606.

39. Ji A, Pan C, Wang H, Jin Z, Lee JH, Wu Q, Jiang Q, Cui L: Prevalence and Associated Risk Factors of Chronic Kidney Disease in an Elderly Population from Eastern China. INT J ENV RES PUB HE 2019, 16(22).

40. Wang LM, Chen ZH, Zhang M, Zhao ZP, Huang ZJ, Zhang X, Li C, Guan YQ, Wang X, Wang ZH et al: [Study of the prevalence and disease burden of chronic disease in the elderly in China]. Zhonghua Liu Xing Bing Xue Za Zhi 2019, 40(3):277-283.

41. Turjamaa R, Kapanen S, Kangasniemi M: How smart medication systems are used to support older people's drug regimens: A systematic literature review. GERIATR NURS 2020, 41(6):677-684.

42. Mauro J, Mathews KB, Sredzinski ES: Effect of a Smart Pill Bottle and Pharmacist Intervention on Medication Adherence in Patients with Multiple Myeloma New to Lenalidomide Therapy. J MANAG CARE SPEC PH2019, 25(11):1244-1254.

43. Islam SMS, Cartledge S, Karmakar C, Rawstorn JC, Fraser SF, Chow C, Maddison R: Validation and Acceptability of a Cuffless Wrist-Worn Wearable Blood Pressure Monitoring Device Among Users and Health Care Professionals: Mixed Methods Study. JMIR MHEALTH UHEALTH2019, 7(10).

44. China Association of the Aging China Quality of Life Development Report for the Elderly (2019). http://www.cncaprc.gov.cn/llxw/190786.jhtml. Accessed 24 October 2021.

45. Roberts AR, De Schutter B, Franks K, Radina ME: Older Adults' Experiences with Audiovisual Virtual Reality: Perceived Usefulness and Other Factors Influencing Technology Acceptance. Clin Gerontol 2019, 42(1):27-33.

46. Tural E, Lu D, Austin CD: Safely and Actively Aging in Place: Older Adults' Attitudes and Intentions Toward Smart Home Technologies. Gerontol Geriatr Med 2021, 7:1692906884.

47. Dermody G, Fritz R, Glass C, Dunham M, Whitehead L: Factors influencing community-dwelling older adults' readiness to adopt smart home technology: A qualitative exploratory study. J ADV NURS 2021.

48. Graves JM, Abshire DA, Amiri S, Mackelprang JL: Disparities in Technology and Broadband Internet Access Across Rurality: Implications for Health and Education. FAM COMMUNITY HEALTH2021, 44(4):257-265.

49. CNNIC. the 46th Statistical Report on the Development Status of the Internet in China_Departmental Government_Chinese Government Website. http://www.gov.cn/xinwen/2020-09/29/content_5548176.htm. Accessed 24 October 2021.

50. Curtis ME, Clingan SE, Guo H, Zhu Y, Mooney LJ, Hser Y: Disparities in digital access among American rural and urban households and implications for telemedicine-based services. J RURAL HEALTH2021.

51. Mishori R, Antono B: Telehealth, Rural America, and the Digital Divide. J Ambul Care Manage 2020, 43(4):319-322. 
52. Chen X, Orom H, Hay JL, Waters EA, Schofield E, Li Y, Kiviniemi MT: Differences in Rural and Urban Health Information Access and Use. J RURAL HEALTH2019, 35(3):405-417.

53. Resnick MJ: Re: Differences in Starting Pay for Male and Female Physicians Persist; Explanations for the Gender Gap Remain Elusive. J Urol 2020, 204(2):376-377.

54. Barry J: Real wage growth in the U.S. health workforce and the narrowing of the gender pay gap. HUM RESOUR HEALTH2021, 19(1):105.

55. Jonsson KR, Oberg G, Samkange-Zeeb F, Adjei NK: Determinants and impact of role-related time use allocation on self-reported health among married men and women: a cross-national comparative study. BMC PUBLIC HEALTH 2020, 20(1):1204.

56. Del BD, Oggero N, Profeta P, Rossi M: Women's and men's work, housework and childcare, before and during COVID19. Rev Econ Househ 2020:1-17.

57. Lee CC, Czaja SJ, Moxley JH, Sharit J, Boot WR, Charness N, Rogers WA: Attitudes Toward Computers Across Adulthood From 1994 to 2013. GERONTOLOGIST 2019, 59(1):22-33.

58. Goswami A, Dutta S: Gender Differences in Technology Usage-A Literature Review. Open Journal of Business and Management 2016, 04(01):51-59.

59. Yang C, Wu CC: Gender and internet consumers' decision-making. Cyberpsychol Behav 2007, 10(1):86-91.

60. Greier K, Drenowatz C, Ruedl G, Riechelmann H: Association between daily TV time and physical fitness in 6- to 14year-old Austrian youth. Transl Pediatr 2019, 8(5):371-377.

61. Burns E, Kakara R: Deaths from Falls Among Persons Aged >/=65 Years - United States, 2007-2016. MMWR Morb Mortal Wkly Rep 2018, 67(18):509-514.

62. Raghunath N, Pereyda C, Frow JF, Cook D, Schmitter-Edgecombe M: Learning-Enabled Robotic Assistive Support: Understanding Older Adult Opinions and Comparing Them to Younger Adult Opinions. Gerontechnology 2020, 19(3).

63. Siering L, Ludden G, Mader A, van Rees H: A Theoretical Framework and Conceptual Design for Engaging Children in Therapy at Home-The Design of a Wearable Breathing Trainer. J Pers Med 2019, 9(2).

64. Burrows A, Meller B, Craddock I, Hyland F, Gooberman-Hill R: User involvement in digital health: Working together to design smart home health technology. HEALTH EXPECT 2019, 22(1):65-73.

65. Pal D, Funilkul S, Vanijja V, Papasratorn B: Analyzing the Elderly Users' Adoption of Smart-Home Services. IEEE ACCESS 2018, 6:51238-51252.

\section{Figures}




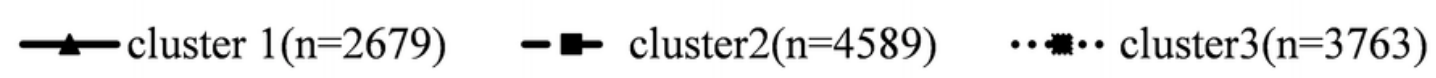

\section{5}
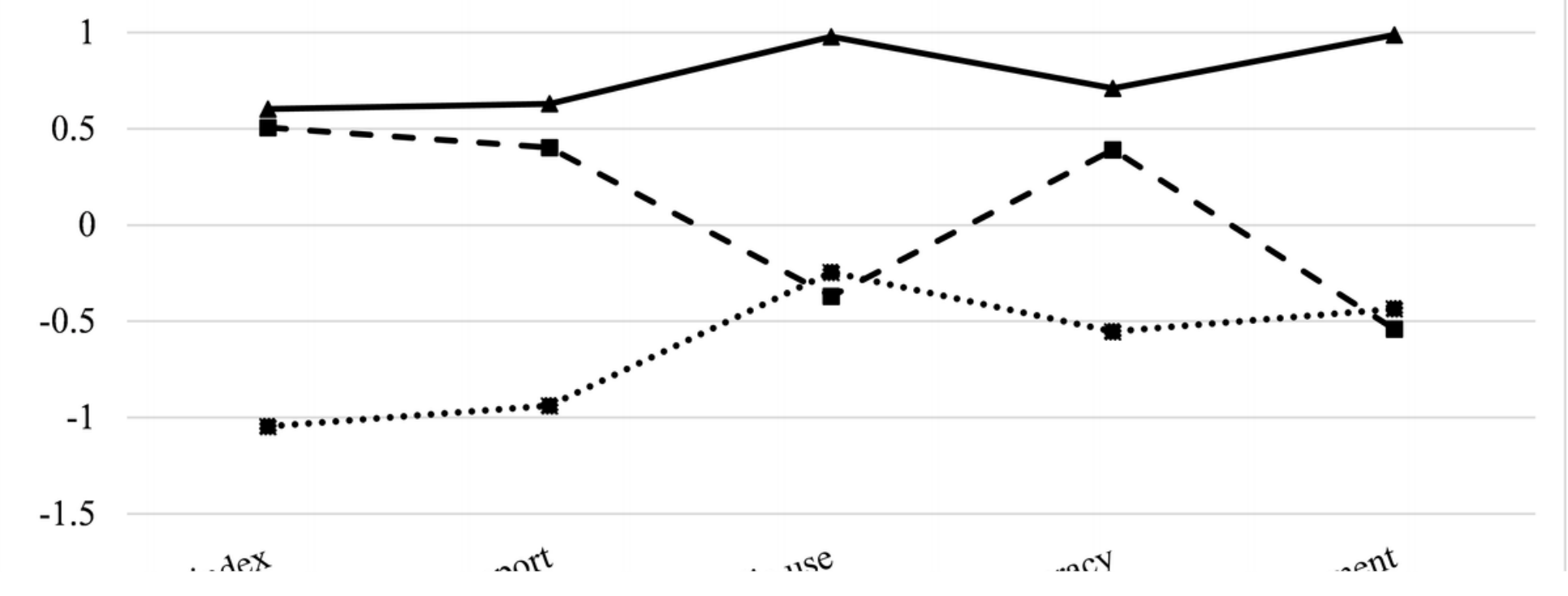

\section{Figure 1}

Clusters for health-related risk factors.

Note: The definition of the classes: class 1 , low risk; class 2, middle risk; class 3 , high risk.

Self-management: chronic disease self-behavioral management.

\section{Supplementary Files}

This is a list of supplementary files associated with this preprint. Click to download.

- SupplementaryMaterials.docx

- database.xlsx 